\title{
A Response to Mark Unsworth: Cui Bono?
}

In the November 2014 issue of Policy Quarterly Mark

Unsworth, a partner at Saunders Unsworth, a lobbying and public policy consultancy, asks the question: was the Lobbying Disclosure Bill a solution to a problem that does not exist? He then states: 'Apart from the Green Party and some in academia, this was never a burning issue in NZ ...their strongest argument seems to be that $\mathrm{NZ}$ needs it because other countries have it.' In support of this assertion he very selectively cites one of the conclusions from

\section{Transparency International New Zealand's 2013 National Integrity System Assessment, to the effect that NZ's national integrity system remains fundamentally strong, and that by international standards there is very little corruption in NZ.}

Unfortunately Unsworth omitted to refer to the overall conclusion of the TINZ report, which was contained in two places in the summary article he cites and which features prominently in the report itself:

The core message of this report is that it is beyond time for serious and urgent action to protect and extend integrity in New Zealand.

Among the factors analysed in the report and cited in the Executive Summary that raise serious concerns about the influence of lobbyists are:

- Forty four per cent of respondents in the New Zealand Survey of Values 2005 thought the country was run by a few big interests looking after themselves rather than for the benefit of all people. Whether this perception is true or not, the fact that nearly half of those surveyed believe the country is run by a few big interests for their own benefit reflects a damaging lack of faith in our democracy.
One of the four main weaknesses identified in the integrity of NZ's governance systems was the interface between political party finances and public funding, including the transparency of political party financing and of donations to individual politicians.

- Conflicts of interest are not always well managed in NZ's relatively small society.

Flowing from this analysis - which was supported by in-depth research by a number of independent and respected analysts - the report recommended the introduction of

... measures that provide an adequate degree of transparency to ensure that public officials, citizens, and businesses can obtain sufficient information on, and scrutinise lobbying of members of Parliament and ministers (Recommendation 3.a.v).
Unsworth also briefly compares the risks from lobbying in NZ to a few selected other countries - Australia, the UK, and the USA, which he describes as 'neighbours' and as 'close allies.' Unsworth does not explain why we should compare NZ to the USA. We may or may not be 'close allies' but the USA has vastly different constitutional, historical, social and economic characteristics, factors that are usually considered relevant criteria when making cross-country comparisons in public policy. Could it be that Unsworth is using the USA as a 'straw man', to facilely conclude that, compared to the USA, NZ does not have a problem with the lobbying industry?

On the evidence of the TINZ National Integrity System Assessment there is a real concern about undue private influences on public policy in NZ; and, perhaps not surprisingly, on the evidence of Unsworth's article, it demonstrates the challenges of having an objective discussion about conflicts.

\section{Murray Petrie}

Senior Associate, Institute of Governance and Policy Studies, Victoria University of Wellington.

Co-Director of the TINZ 2013 National Integrity System Assessment.

Liz Brown

Research Team Leader,

TINZ 2013 National Integrity System

Assessment.

Suzanne Snively

Co-Director of the TINZ 2013 National Integrity System Assessment. 